\title{
Professionals in Food Chains
}

\section{Svenja Springer ${ }^{1} \cdot$ Christian Dürnberger $^{1} \cdot$ Matthias Eggel $^{2}$}

Published online: 6 July 2019

(C) Springer Nature Switzerland AG 2019

In recent years, a growing ethical awareness of food production and consumption can be observed. While people appreciate increased food safety and low food prices (Boogaard et al. 2008, 2011), they are increasingly concerned about social and ecological aspects (Luhmann and Theuvsen 2016) and in particular about animal welfare issues (e.g. Bergstra et al. 2017; Clark et al. 2016; Krystallis et al. 2009). In other words, the corresponding debates are not only concerned with sufficient nutrition and quality of products, but also deal with responsibilities towards animals, future generations and the environment. Since food has always been a very emotional topic, it is not surprising that the on-going debates are often controversial, passionate and sometimes even escalating; furthermore, these debates are exacerbated by the complexity of modern food systems. At the same time, global challenges through climate change, population growth and unsustainable practices have become urgent issues. Against this background, various disciplines are working in a new emerging field that can be labelled with the name of this journal: Food ethics. How we produce our food and what we consume has consequences of high moral importance and pose questions at the intersection of philosophy, law, politics, economics, sociology, veterinary medicine, agricultural science, etc. (see e.g. also Olsson et al. 2016; Springer and Grimm 2018).

Despite (and/or independent of) the widely discussed "attitude-behaviour"-gap (e.g., Bray et al. 2011; Carrington et al. 2010), it is often argued that the key to meeting current ethical challenges is changing consumer behaviour: Reports indicate a shift of market power towards the consumer (Murphy and Bendell 2001), understanding consumption as voting (Shaw et al. 2006), since an increasing number of people follow a concept of consumer citizenship (Lang and Gabriel 2005), trying to act beyond their own immediate interests and considering the

\section{Svenja Springer}

svenja.springer@vetmeduni.ac.at

Christian Dürnberger

christian.duernberger@vetmeduni.ac.at

Matthias Eggel

matthias.eggel@ibme.uzh.ch

1 Unit of Ethics and Human-Animal Studies, Messerli Research Institute, University of Veterinary Medicine, Medical University of Vienna, and University of Vienna, Veterinaerplatz 1, 1210 Vienna, Austria

2 Institute for Biomedical Ethics and History of medicine, University of Zurich, Winterthurerstrasse 30, 8006 Zurich, Switzerland 
consequences of their choices on society in general (Doane 2001). However, it must be questioned whether emerging challenges can be met solely with the will to change how consumers decide in the supermarket - as the last link in the food chain.

For this reason, this special issue focuses on a group that are normally only in the limelight when the media are reporting so called "food scandals": professionals and practitioners along the food chain like farmers, retailers, or veterinarians. To understand and get a grip on current and future problems in the food chain, attention to the different roles and positions of professionals is essential. Participating players act in different areas of responsibility and are subject to their specific expertise, professional values and virtues. Thus, different agendas, expectations and interests inevitably lead to challenging and complex situations for all involved parties in trying to get to the bottom of the problems.

In June 2018, the interdisciplinary Messerli Research Institute hosted the EurSafe Conference on "Professionals in Food Chains: Ethics, Roles and Responsibilities" to enable a scientific discussion with questions regarding the role of participating players in the food chain, professionals' varying responsibilities and emerging ethical challenges. The topics ranged from fundamental issues in ethics to veterinary medicine, from transparency in the food chain to animal welfare, exposing problem areas and suggesting guidelines in how to deal with them. Taking the EurSafe Conference 2018 as a starting point, this special issue on "Professionals in Food Chains" aims to unite contributions from various disciplines and provides a format to deepen investigations and discussions of the aforementioned challenges.

The first contribution investigates factors of communication that encourage managers in their responsible behaviour towards animals in companies. By means of a qualitative study, Janssens and van Wessel identified two different ways of managers' communication strategies to promote the company's ethical position: firstly, the connection between stakeholders within and outside the company, and secondly, the facilitation of communicative connections between different stakeholders in which the manager is not directly involved. The authors provide an overview of the total field of communication around managers as well as communicative tools, which help them to strengthen and communicate their responsibility towards the animals in animal-based food industry.

The paper by Bernhardt, Risius and Spiller aims to gain empirical knowledge concerning inspectors' role in the process of certification within the organic farming system. The authors provide insights into the inspectors' strategies and action patterns to better understand their behaviour in the process of certification. Results of their study indicate that inspectors' strategies and behavioural patterns can be assigned to two levels. First, the authors describe the interpersonal level, where inspectors' behaviour patterns range from benevolence arising from operator appreciation to demonstration of decision-making power in difficult situations. Further, the data refer to a second level - the professional one - where organic inspectors show action patterns with regard to the execution of control, where inspectors work with a risk or checklist-oriented approach. On the basis of their results, Bernhardt and Spiller conclude that different professional action patterns mirror the development of the organic sector in Germany and that an enhancement and stabilization of the certification system should be accompanied by an on-going professionalization of the sector to manage the balancing act between different small organic farms and large companies providing organic products.

Schulze, Spiller and Risius focus their attention on a further important role in the food chain, namely the role of retailers as gatekeepers between farmers and consumers. The authors attribute to this role a high sphere of influence and responsibility when it comes to products with a higher animal welfare standard. By means of in-depth interviews with representatives of the food retail industry, the authors explored factors which motivate retailers to take on the 
marketing of products of increased animal welfare standards by using the example of pasturebased beef. Beside the identification of intrinsic and extrinsic motives, the study shows that there exist innovative retailers, whose role exceed the classical distribution function and have a considerable effect in transforming the food system in regard to animal welfare standards.

The questionnaire-based study conducted by Hölker, Meyer-Höfer and Spiller contributes to a deeper understanding of which animal-ethical values may influence the behaviour of consumers. By using a structural equation model, the authors found that animal-ethical intuitions can be integrated into the value system as domain specific values, and ascertained that in particular anthropocentrism and abolitionism - as two extreme positions - significantly affect consumer behaviour in cases of game meat consumption.

The paper of Whitfort addresses the implementation of so called "Ag-gag" laws in USA and Australia as new legislation to prohibit the dissemination and publication of recordings and photographs showing the conditions of animals on farms and in abattoirs. The author particularise that such controls have a negative effect regarding the transparency in the food chain and accountability of involved persons responsible for the management of animals. Whitfort thoroughly describes the recent legal challenges in the USA to the constitutionality of "Ag-gag" and evaluates the impact of the new legislation on animal welfare in agricultural facilities.

Huth, Weich and Grimm question in their paper the single conceptualization of health within the One Health concept by arguing that there is not one single underlying logic to comprehend and ethically reflect all veterinary interventions. They propose to differentiate between an objectivist, a functional, and a sentientistic frame of health as a multi-layered and complex concept. Further, the authors take the view that this differentiation might decrease veterinarians' moral stress by meeting the requirements of contradicting practices within the veterinary profession.

Likewise, the paper authored by van Herten and Meijboom also investigates veterinarians' role and responsibilities within the One Health concept by questioning how veterinarians should deal with situations in which measures to protect public health have negative effects for animal health. The authors suggest a holistic perspective on One Health in order to strengthen the veterinarian's position and to deal with occurring moral problems. They introduce an 'encapsulated health' argument, which focuses on the veterinarian's central responsibility as the expert in animal health and welfare and consequently serve public health.

We sincerely thank the authors for their valuable contributions to this special issue. Further, we would like to thank all reviewers for taking time to provide their expertise during the double-blind review process as well as Jenine Navarro (Springer Publisher) for her administrative and organizational support during the publication process. We would like to thank Anne Algers and Matthias Kaiser (editors in chief) for the opportunity to publish the special issue in the Journal of Food Ethics.

We are very pleased to be able to showcase multiple perspectives of new and innovative approaches at the intersection of philosophy, law, veterinary medicine and sociology, and hope that the contributions will help to stimulate a lively and fruitful debate on issues related to professionals in food chains.

The editors

Svenja Springer

Christian Dürnberger

Matthias Eggel 


\section{References}

Bergstra, T.J., H. Hogeveen, and E.N. Stassen. 2017. Attitudes of different stakeholders toward pig husbandry: a study to determine conflicting and matching attitudes toward animals, humans and the environment. Agriculture and Human Values 34 (2): 393-405. https://doi.org/10.1007/s10460-016-9721-4.

Boogaard, B.K., S.J. Oosting, and B.B. Bock. 2008. Defining sustainability as a socio-cultural concept: Citizen panels visiting dairy farms in the Netherlands. Livestock Science 117: 24-33.

Boogaard, B.K., B.B. Bock, S.J. Oosting, J.S.C. Wiskerke, and A.J. van der Zijpp. 2011. Social acceptance of dairy farming: the ambivalence between the two faces of modernity. Journal of Agricultural and Environmental Ethics 24 (3): 259-282. https://doi.org/10.1007/s10806-010-9256-4.

Bray, J., N. Johns, and D. Kilburn. 2011. An exploratory study into the factors impeding ethical consumption. Journal of Business Ethics 98 (4): 597-608.

Carrington, M.J., B.A. Neville, and G.J. Whitwell. 2010. Why ethical consumers don't walk their talk: Towards a framework for understanding the gap between ethical purchase intentions and actual buying behaviour of ethically minded consumers. Journal of Business Ethics 97 (1): 139-158.

Clark, B., G.B. Stewart, L.A. Panzone, and L.J. Frewer. 2016. A Systematic Review of Public Attitudes, Perceptions and Behaviours Towards Production Diseases Associated with Farm Animal Welfare. Journal of Agricultural and Environmental Ethics 29 (3): 455-478. https://doi.org/10.1007/s10806-016-9615-x.

Doane, D. 2001. Taking Flight: The Rapid Growth of Ethical Consumerism. London: New EconomicsFoundation.

Krystallis, A., M.D. de Barcellos, J.O. Kügler, W. Verbeke, and K.G. Grunert. 2009. Attitudes of European citizens towards pig production systems. Livestock Science 126: 46-56.

Lang, T., and Y. Gabriel. 2005. A brief history of consumer activism. In Harrison, R., Newholm, T. and Shaw, D. (Eds), The Ethical Consumer, 39-53. London: Sage.

Luhmann, H., and L. Theuvsen. 2016. Corporate Social Responsibility in Agribusiness: Literature Review and Future Research Directions. Journal of Agricultural and Environmental Ethics 29 (4): 673-696. https://doi. org/10.1007/s10806-016-9620-0.

Murphy, D., and J. Bendell. 2001. Getting enganged: Business-NGO Relations on Sustainable Development. In The Earthscan Reader in Business and Sustainable Development. Eds, ed. R. Starkey and R. Welford. London: Earthscan Publications.

Olsson, I.A.S., S.M. Araújo, and M.F. Vieira, eds. 2016. Food futures: Ethics, science and culture. Wageningen: Wageningen Academic Publishers.

Shaw, D., T. Newholm, and R. Dickinson. 2006. Consumption as voting: An exploration of consumer empowerment. European Journal of Marketing 40 (9/10): 1049-1067.

Springer, S., and H. Grimm, eds. 2018. Professionals in food chains. Ethics, roles and responsibilities. Wageningen: Wageningen Academic Publishers.

Publisher's Note Springer Nature remains neutral with regard to jurisdictional claims in published maps and institutional affiliations. 